\title{
Comparison of Sterile and Clean Dressing Techniques in Post-operative Surgical Wound Infection in a Chinese Healthcare Facility
}

\author{
Xiao-ling Huang ${ }^{1}$, Jing-qi Zhang ${ }^{2}$, Shu-ting Guan ${ }^{3}$ and Wu-jin Liang ${ }^{4 *}$ \\ ${ }^{1}$ Department of Nursing, ${ }^{2}$ Department of Soft Traumatology, ${ }^{3}$ Department of Endocrinology, ${ }^{4}$ Department of Nursing College, \\ Changchun University Of Chinese Medicine,Changchun130017, China
}

*For correspondence: Email: wujingliang2@hotmail.com; Tel/Fax: 0086-431-81953713

Received: 6 February 2015

Revised accepted: 19 December 2015

\begin{abstract}
Purpose: To investigate the effect of sterile and clean dressing techniques on wound management in a Chinese hospital, and to compare their impact on wound healing and the cost of the dressing materials with respect to postoperative surgical wounds.

Methods: A total of 130 patients, comprising 70 (53.8\%) males and 60 (46.2\%) females, who had undergone surgery in The Affiliated Hospital of Changchun Traditional Chinese Medicine University, Changchun, China in 2012 - 2014 were enrolled in the study. Of these, 65 (50\%) received sterile dressings and 65 (50\%) clean dressings. A control group comprising 25 patients, 15 (60\%) males and $10(40 \%)$ females, who attended the clinic for change dressings only, was also included. The patients' dressings were changed four times daily with $2 x$ sterile and $2 x$ clean dressings. Details of all the changes, including the nutritional status of the patients, were recorded. The patients were followed-up up to the time of their discharge.

Results: Twelve (18.5\%) patients out of those who received sterile or clean dressings were found to have acquired an infection. The size of the wounds was approximately 1.8 to $32.4 \mathrm{~cm}^{3}$ (mean: $5.2 \pm 6.4$ $\mathrm{cm}^{3}$ ) in size at the start of the study and 0.6 to $4.2 \mathrm{~cm}^{3}$ at the end of the study. A significant difference was identified between the sterile and clean dressing groups at the beginning of the study $(U=72.5 ; p<$ 0.12). A decrease in wound size was observed in both of these groups but was not statistically significant, while the change in wound volume, was significantly different $(U=84.5 ; p<0.25)$. When the cost of the two dressing types was compared, the sterile items were more expensive than that of the clean items; thus, sterile dressing procedure was significantly more costly than clean dressing procedure $(p<0.01)$.

Conclusion: With mounting concern regarding antimicrobial resistance and hospital-acquired infections, suitable wound dressing techniques are required to prevent infection and reduce the duration of wound healing after surgery without compromising patient safety.
\end{abstract}

Keywords: Wound dressing, Postoperative, Antimicrobial resistance, Hospital-acquired infections

Tropical Journal of Pharmaceutical Research is indexed by Science Citation Index (SciSearch), Scopus, International Pharmaceutical Abstract, Chemical Abstracts, Embase, Index Copernicus, EBSCO, African Index Medicus, JournalSeek, Journal Citation Reports/Science Edition, Directory of Open Access Journals (DOAJ), African Journal Online, Bioline International, Open-J-Gate and Pharmacy Abstracts

\section{INTRODUCTION}

Wound infections are the most common serious infections acquired after surgical procedures and lead to prolonged hospital stays and higher treatment costs [1-3]. The crucial period for an infection to become established is during the 
initial few hours after the wound is first infected with bacteria [4].

The most important component of wound management is the use of sterile techniques for changing the dressings of patients with open surgical wounds [5,6]. Sterile dressing techniques have been adopted to aid healing and avoid infection and are considered to be the 'gold standard' for the management of surgical wounds [7]. Hospital-acquired infections (HAls) account for $38 \%$ of all wound infections $[8,9]$, and the hospital's healthcare management is liable for the economic impact of such infections [10]. Therefore, an unequivocal relationship exists between HAls and wound management [9]. The risk of acquiring a HAI can be reduced by the optimal management of wounds by nursing staff. Failure to do so risks patient safety and exposes the patient to infection [11].

Almost $15 \%$ of HAls have their origins in infected surgical wounds - the third most common type of HAl. Because of this, the Center for Disease Control recommends application of sterile dressings during the first $24-48 \mathrm{~h}$ following surgery and then clean dressing changes after $48-72 \mathrm{~h}[12,13]$. This survey was undertaken to investigate the effects of sterile and clean dressings on wound care and to compare wound healing and the comparative cost of sterile and clean dressing procedures for postoperative surgical wounds. This study also explores the conditions under which nurses perform sterile and clean wound dressing techniques.

\section{EXPERIMENTAL}

A total of 130 patients who underwent surgery at our hospital were included in the study. Of these, 70 (53.8 \%) were males and 60 (46.2 \%) females. The study was conducted in a Chinese hospital during the period 2012 - 2014. This study was approved by the Institutional Ethical Committee of the Affiliated Hospital of Changchun Traditional Chinese Medicine University, Changchun, China (ref number: ICE0732/953) $[7,15]$.

All surgical patients aged $20-60$ years who were scheduled for dressing changes after the first $24 \mathrm{~h}$ were initially included in the study. Patients with exposed tendons, those who were discontinued from the study within 2 days after surgery, and pediatric patients were excluded. Of the total number of patients, $65(50 \%)$ received sterile dressings (the sterile group) and 65 (50 $\%$ clean dressings (the clean group). Mean patient age was 36.4 years for the sterile group and 40.1 years for the clean group. A control group of 25 patients who attended our hospital for wound dressings only, following surgery at a different hospital, were included in our study. In the control group, $15(60 \%)$ patients were male and $10(40 \%)$ female. However, one (4\%) control patient was discontinued from the study due to unknown reasons. The control group comprised 12 (48\%) patients who received sterile dressings and 12 (48 \%) patients who received clean dressings. The mean age of the control group patients who received sterile dressings was 38.9 years, and that of those who received clean dressings was 42.2 years.

The two types of dressing techniques considered in this study are as follows:

\section{Sterile dressing technique}

This refers to the replacement of the wound dressing following aseptic techniques and using sterile items;

\section{Clean dressing technique}

This refers to the substitution of the wound dressing with a new dressing after medicinal asepsis using clean but non-sterile items.

Gauze cloth was used for the dressing material in both techniques, since it is coarse and can be moistened with a sterile saline solution.

The two methods were regarded as independent variables, whereas the cost and wound healing were considered to be dependent variables, for the purposes of statistical analysis. Sterile and clean dressing items, such as gauze, cotton, and gloves, were included under the cost criteria. The use of each item was noted for all patients, and their associated cost was estimated. The demographic details, such as age and sex, of all patients and other variables such as wound infection, immunologic status, and nutritional status were also recorded.

The infected wound of each discharged patient was monitored for 20 postoperative days. Samples of size $1.5 \mathrm{~cm} \times 1.5 \mathrm{~cm}$ were collected under aseptic conditions and delivered to the microbiology laboratory. A thioglycolate broth was added to each sample, and the samples were then incubated at $37^{\circ} \mathrm{C}$ for $48 \mathrm{~h}$ in ambient air. The plates were further incubated at $37^{\circ} \mathrm{C}$ for $24 \mathrm{~h}$. If growth occurred, the organisms were identified using automated means [13,14]. The patients' nutritional condition was assessed by analyzing the serum albumin level, which plays 
an important role in wound healing, while a lymphocyte count was performed to determine the immunological status of each patient. The latter test was conducted $48 \mathrm{~h}$ after the patient had a positive culture report.

\section{Protocol}

Before the nurses were enrolled in our study, they first underwent training for 3 months for both sterile and clean dressing methods until they were able to perform the procedures with no errors.

Wounds were assessed by a physician each time the dressings were changed. The dressings of each patient were labeled to help avoid confusion for the physicians and nurses. Informed consent was obtained from every patient. Dressings were changed at the bedside four times each day using $2 x$ sterile and $2 x$ clean dressings. Each change was documented, as were the healing status of the wound and other variables such as the patient's nutritional status. Follow-up was conducted until discharge of the patient.

\section{Statistical analysis}

Statistical analysis was performed using the SPSS software version 21.0 (IBM Corp., Armonk, NY, USA). Mean \pm standard deviation (SD) was calculated and the data were analyzed using a Mann-Whitney $U$ test. Differences at $p>0.01$ ) were considered statistically significant.

\section{RESULTS}

Tables 1 and 2 provide a comparison of the recorded variables between dressing types for each group.

According to the National Research Council [7], wound contamination classification (i.e., clean, clean-contaminated, contaminated, dirty) is made based on the risk of acquiring infection. Diabetes is a common factor in wound healing and was detected in $82(63.1 \%)$ patients of both sexes in our study. In addition, 24 (18.5\%) patients were hypertensive (Table 3).

Mann-Whitney $U$ test, performed to differentiate between the sterile and clean dressing groups, revealed that $12(18.5 \%)$ patients in each group had acquired an infection. Both infected groups were retained in our study and were given appropriate antibiotic treatment according to the physician's prescription, e.g., ciprofloxacin (500 $\mathrm{mg}$ ), or cefotaxime $(1-2 \mathrm{~g})$ via an intravenous route.

Table 1: Comparison of variables for the study group

\begin{tabular}{lcc}
\hline Variable & $\begin{array}{c}\text { Sterile } \\
(\mathbf{N}=65)\end{array}$ & $\begin{array}{c}\text { Clean } \\
(\mathbf{N}=65)\end{array}$ \\
\hline Age (years) & & \\
Mean & 36.4 & 40.1 \\
SD & 12.2 & 12.8 \\
\hline Serum albumin $(\mathbf{g} / \mathbf{d L})$ & & \\
Mean & 2.8 & 3.2 \\
SD & 0.5 & 0.4 \\
\hline Lymphocyte count (cells $\left./ \mathbf{m m}^{3}\right)$ & & \\
Mean & 1043 & 894 \\
SD & 428 & 256 \\
\hline
\end{tabular}

Table 2: Comparison of variables for the control group

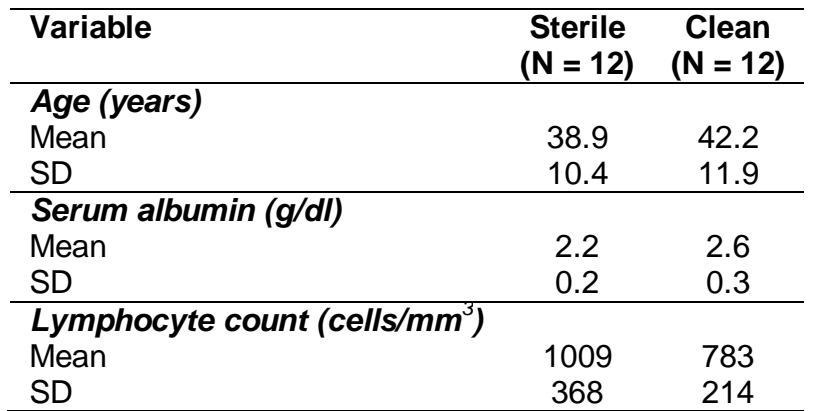

$P>0.05$ (Mann-Whitney test)

Table 3: Variables of the patients in study and control groups

\begin{tabular}{lccc}
\hline Variable & $\begin{array}{c}\text { Sterile } \\
(\mathbf{N}=\mathbf{6 5})\end{array}$ & $\begin{array}{c}\text { Clean } \\
(\mathbf{N}=\mathbf{6 5})\end{array}$ & $\begin{array}{c}\text { Control group } \\
(\mathbf{N}=\mathbf{2 5})\end{array}$ \\
\hline Weight $(\mathrm{kg})$ & $74 \pm 12$ & $73 \pm 10$ & $70 \pm 14$ \\
Height $(\mathrm{cm})$ & $148 \pm 10$ & $150 \pm 12$ & $147 \pm 15$ \\
Diabetes & 42 & 39 & 16 \\
Hypertension & 12 & 12 & 14 \\
Hemoglobin $(\mathrm{g} / \mathrm{dl})$ & $14 \pm 2.0$ & $12.6 \pm 1.9$ & $12.1 \pm 2.2$ \\
Duration of antibiotics post-surgery (days) & $2.5 \pm 3.0$ & $2.5 \pm 3.0$ & $2 \pm 2.5$ \\
Infected wound post-surgery $(\%)$ & 14.5 & 14.5 & 26.6 \\
Healing rate (beginning of study) $\left(\mathrm{cm}^{3}\right)$ & $1.8-32.4$ & $1.5-30.4$ & $2.1-34.8$ \\
Healing rate (end of study) $\left(\mathrm{cm}^{3}\right)$ & $0.6-4.2$ & $0.8-4.6$ & $1.5-5.2$ \\
\hline
\end{tabular}



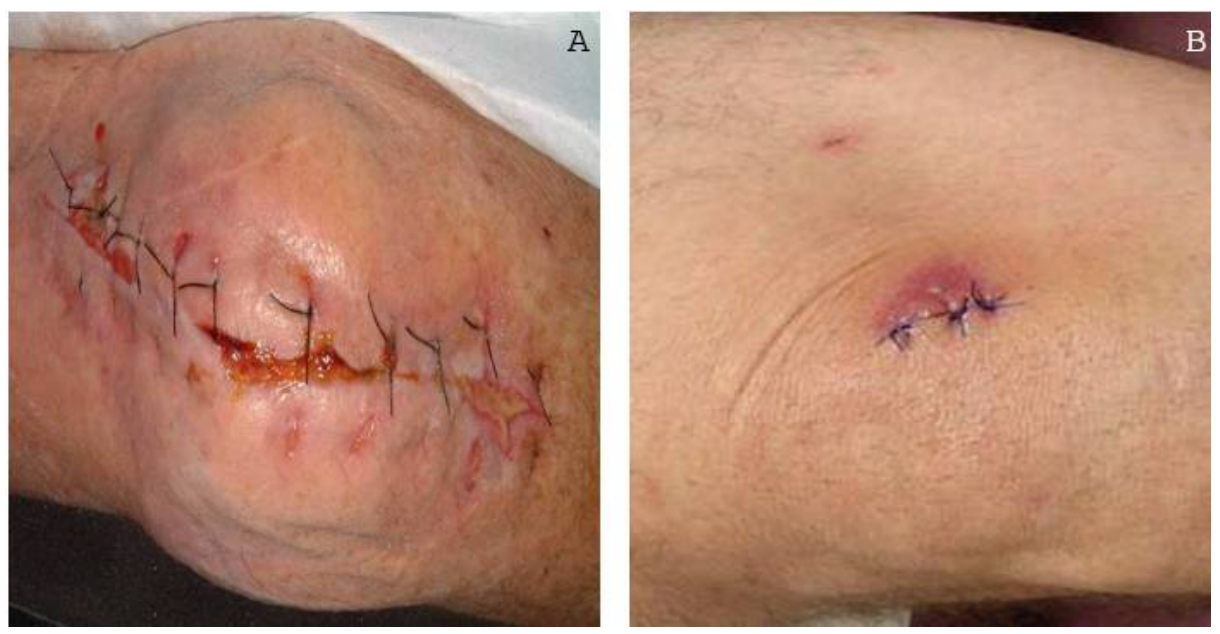

Figure 1: a) The wound size after 4 days post-surgery showing evidence of infection. b) The healed wound after effective wound management (35 days post-surgery)

The healing wounds were measured at the beginning of the study and were found to be approximately $1.8-32.4 \mathrm{~cm}^{3}$ (mean: $5.2 \pm 6.4$ $\mathrm{cm}^{3}$ ) in size. They were again measured at the end of the study, and the size ranged from 0.6 to $4.2 \mathrm{~cm}^{3}$. A significant difference was identified between the two groups at the beginning of the study $(U=72.5 ; p<0.12)$ (Fig 1a).

A decrease in the size of the wound was observed in both groups. On statistical analysis, no significant difference was found in either study group. When the wound volume was compared, a significant difference was identified Mann Whitney $U$ test, $U=84.5 ; p<0.25$ ) (Fig. 1b).

When the cost of the two dressings was compared, the sterile items were found to be more expensive than the clean items, and therefore the sterile dressing procedure was significantly more expensive than the clean procedure $(p<0.01)$.

\section{DISCUSSION}

Our study compared the time taken for wound healing to occur between sterile and clean dressing procedures. A previous study highlighted a heavy bio-burden potentially delaying wound healing [15-20]. The present study consisted of 65 patients divided into two groups: one group received sterile dressings and the other clean dressings. Control patients were also divided into these two groups, consisting of 12 patients each. When the study and control group patients were compared, significant differences were found in terms of the age of the patients and the progression of wound healing at both the beginning and end of the study in both study groups. Our study corroborates other studies, which have reported similar findings [21]. A serum albumin level below $3.0 \mathrm{~g} / \mathrm{dl}$ and a lymphocyte count of less than 1500 cells $/ \mathrm{mm} 3$ suggests that the patient's nutritional status is inadequate and that the patient is malnourished [22]. In many previous studies concerning sterile and clean dressing procedures, the patients were followed-up for only a short period. However, in our study the patients were followed-up until discharge from the hospital, and this adds strength to the findings [21].

The cost of the sterile dressings was relatively high compared with dressings used for the clean procedures. In a developing nation like ours where cost is a deciding factor, clean dressings are preferred, and thus there is a demand for improvements in the quality of clean dressing.

No significant differences between the sterile and clean dressing procedures were found, sterile procedures are safer for patients. All of the patients in our study were adults with high levels of immunity. However, if the same study was conducted in a pediatric population, the level of immunity of the patients and the dressing procedures used may raise questions for further research [23]. In addition, regular wound care audits should be compulsory, and it is recommended that nurses self-assess how to carry out dressing procedures to lower the risk of infection [9].

\section{Limitations of the study}

This study has some limitations. First, it targeted adult patients with high levels of immunity, but if the same study was conducted in a pediatric population, the level of immunity and the dressing procedures required may raise further 
questions not addressed here. Therefore, further research is required. Moreover, the cost effectiveness of the sterile dressings should be placed in proper perspective since they are not affordable to all patients.

\section{CONCLUSION}

With rising concern regarding antimicrobial resistance and hospital-acquired infections, wound dressing techniques need to be performed to prevent infection and reduce the duration of wound healing after surgery without compromising patient safety. It is recommended that all nurses understand and carry out safe wound dressing procedures to avoid the spread of hospital-acquired infections as a direct consequence of changing dressings.

\section{REFERENCES}

1. Haley RW, Culver DH, Morgan WM, White JW, Emori TG, Hooton TM. Identifying patients at high risk of surgical wound infection: a simple multivariate index of patient susceptibility and wound contamination. Am J Epidemiol 1985; 121: 206-215.

2. Kurz $A$, Sessler $D I$, Lenhardt $R$. Perioperative normothermia to reduce the incidence of surgical-wound infection and shorten hospitalization. N Engl J Med 1996; 334: 1209-1215.

3. Bremmelgaard A, Raahave $D$, Beier-Holgersen $R$, Pedersen JV, Andersen S, Sorensen Al. Computeraided surveillance of surgical infections and identification of risk factors. J Hosp Infect 1989; 13: 118.

4. Melling AC, Ali B, Scott EM, Leaper DJ. Effects of preoperative warming on the incidence of wound infection after clean surgery: a randomised controlled trial. The Lancet 2001; 358: 876-880.

5. Shah JB. The History of Wound Care. J Ame Col Cert Wound Special 2011; 3: 65-66.

6. Lewis SM, Collier IC. Medical-surgical nursing: assessment and management of clinical problems. 3rd edN. St. Louis: Mosby-Year Book, 1992.

7. Bratzler DW, Schecter PW, Umscheid C. CDC and HICPAC DRAFT Guideline for Prevention of Surgical Site Infection, 2014

8. Ford $D$, Koehler $S$. A creative process for reinforcing aseptic technique practices. AORN J. 2001; 73: 446450.
9. Preston R. Aseptic technique: evidence-based approach to patient safety. Br J Nurs 2005; 14: 540-546.

10. Graves N. Economics and preventing hospital-acquired infection. Emerg Infect Dis 2004; 10: 561-566.

11. Gillespie BM, Fenwick C. Comparison of the two leading approaches to attending wound care dressings. JWOCN 2009; 17: 85-89.

12. Jeanne M, Gemender BSN, Reising DL. Investigating nurses' dressing change techniques. Am Nurse Today. 2007: 53-55.

13. Horan TC, Gaynes RP, Martone WJ, Jarvis WR, Emori TG. CDC definitions of nosocomial surgical site infections: a modification of $C D C$ definitions of surgical wound infections. AJIC Am J Infect Control 1992; 20: 271-274.

14. Sherertz R J, Garibaldi RA, Marosok RD, Mayhall CG, Scheckler WE. Consensus paper on surveillance of surgical wound infections. AJIC Am J Infect Control 1992; 20: 263-270.

15. Wolinsky H. Bioethics for the world. EMBO Rep 2006; 7: 354-358.

16. Laato M, Lehtonen OP, Niinikoski J. Granulation tissue formation in experimental wounds inoculated with Staphylococcus aureus. Acta Chir Sc 1985; 151: 313318.

17. Laato $M$, Niinikoski J, Lunberg C. Inflammatory reaction and blood flow in experimental wounds inoculated with Staphylococcus aureus. Eur Surg Res 1988: 2013320138.

18. Kingsley $A$. The wound infection continuum and its application to clinical practice. Ostomy Wound Manage 2003; 49: 1-7.

19. Robson MC, Stenberg BD, Hegger JP. Wound alterations caused by infection. Clin Plastic Surg 1990; 17: 485492.

20. Sarabahi S. Recent advances in topical wound care. Ind J Plast Surg 2012; 45: 379-387.

21. Stotts A, Susan Barbour MS, Kathleen Griggs MS, Brenda Bouvier MS, Lesfie Buhlman BS, Deidre WipkeTevis RN, Donna F, Williams MS. Sterile Versus Clean Technique in Postoperative Wound Care of Patients With Open Surgical Wounds A Pilot Study. JWOCN 1997; 24: 10-18.

22. Moon MS, Kim SS, Lee SY, Jeon DJ, Yoon MG, Kim SS, Moon H. Preoperative Nutritional Status of the Surgical Patients in Jeju. Clin Orthoped Surg 2014; 6: 350-357.

23. Moues CM, Heule F, Legerstee R, Hovius SE: Five millennia of wound care products-what is new? A literature review. Ostomy Wound Manage. 2009; 55: 16-18. 